\title{
A SYSTEMATIC STUDY OF SOFTWARE QUALITY MODELS
}

\author{
Ashwin B. Tomar ${ }^{1}$ and Dr.Vilas. M. Thakare ${ }^{2}$ \\ ${ }^{2}$ P.G. Department of Computer Science, SGB Amravati University, MH, India \\ vilthakare@yahoo.co.in \\ ${ }^{1}$ Siddhant Institute of Computer Application, under Pune University, MH, India \\ mcatomarashwinegmail. com
}

\begin{abstract}
This paper aims to provide a basis for software quality model research, through a systematic study of papers. It identifies nearly seventy software quality research papers from journals and classifies paper as per research topic, estimation approach, study context and data set. The paper results combined with other knowledge provides support for recommendations in future software quality model research, to increase the area of search for relevant studies, carefully select the papers within a set of journals, and conduct more studies on methods used by software industry and researchers.
\end{abstract}

\section{KEYWORDS}

Software Quality, Software Quality Model, McCall model, Dromey model, FURPS model, ISO 9126 model, Techniques, Approach.

\section{INTRODUCTION}

Quality comprises all characteristics and significant features of a product or an activity which relate to the satisfying of given requirements. The totality of features and characteristics of a software product that bear on its ability to satisfy given needs: for example a) Conform to specifications b) The degree to which software possesses a desired combination of attributes c) The degree to which a customer or user perceives that software meets his or her composite expectations (customer satisfaction) d) The composite characteristics of software that determine the degree to which the software in use will meet the expectations of the customer.

Broadly Quality means quality of product, service, information, processes, people, and system. It means ttranslating future needs of the user into measurable characteristics. Quality can be those product features which meet the need of customers and thereby provide product satisfaction. It is the freedom from deficiencies. It is fitness to use. Poor quality of the software product in sensitive systems may lead to loss of human life, permanent injury, mission failure, or financial loss. So the quality of the project should be maintained at appropriate label. There quality models are proposed to improve, built, predict quality of a software product. They decrease the cost of quality. They are the tools for focusing software development [1] efforts. They are used to identify program modules [5] that are likely to be defective. They help in using the resources effectively. Researchers target only those module (their quality will be tested) which are defective and hence resource utilization is very cost effective. Quality model are trained with data. The trained model is applied to modules to estimate their quality.

It is rightly said "What is not measurable make measurable" - Galileo. "You can't control what you can't measure." - DeMarco. Software metrics are measures related to software. They are indicators of process and products and are useful in case of software quality assurance [2]. They alone are often inadequate or ineffective in evaluating software quality. Question arise how do we measure intangible aspect such as "design"? What metric values will indicate "good design"? Quality models come to rescue which is bridge between metrics and characteristics of software. 
International Journal of Software Engineering \& Applications (IJSEA), Vol.2, No.4, October 2011

The goal of the paper is to introduce practitioner, novice with variety of quality models, related topic, estimation methods, technique, approach, methodology, direct and support future quality estimation research. We base our analysis on systematic search of journal and conference paper. None of the researcher earlier has done with related to above topic. We classify the software quality (estimating quality on basis of software quality models) with respect to following research topic, estimation approach, study context and data set.

There were interesting issues to analyze; we posed some research question described in Table 1. The underline motivation for all questions was our goal of investigation and improvement of software quality research. These questions guided the design of the review process. The contribution of this paper is that it will (a) improve the research domain of software quality models (b) help researchers in selecting papers ( c) serve as tool for selecting paper within the set of journals (d) contributes towards listing all method, technique, approach within this domain (e) bridge gap between present and future work on software quality models (f) classifies all type of paper into category listed in Appendix B. (g) influence in improving quality and production (h) save time, effort \& reduce cost (i) help in achieving the objectives of a software quality assurance initiatives.

The remaining part of this paper is organized as follows section 2 describes Literature review, section 3 describe study process i.e. how the papers were classified section 4 reports the study results, section summarized the main recommendation for future research on software quality.

Table 1. Research Motivation

\begin{tabular}{|c|l|}
\hline \multicolumn{1}{|c|}{ Research Question } & \multicolumn{1}{c|}{ Main Motivation } \\
\hline $\begin{array}{c}\text { 1) Which and how many journals } \\
\text { include } \\
\text { Most paper on Software Quality? }\end{array}$ & $\begin{array}{l}\text { Will help researcher with list of journals } \\
\text { etc. }\end{array}$ \\
\hline $\begin{array}{l}\text { 2) Which are the Most Investigated } \\
\text { Topic on Software Quality? }\end{array}$ & $\begin{array}{l}\text { Will help to Identify trends, limitation \& } \\
\text { opportunity of Software Quality }\end{array}$ \\
\hline $\begin{array}{l}\text { 3) What are the Most Investigated } \\
\text { Methods, Techniques? }\end{array}$ & $\begin{array}{l}\text { Will help to Identify trends, limitation \& } \\
\text { opportunity of Software Quality Methods, } \\
\text { Techniques. }\end{array}$ \\
\hline $\begin{array}{l}\text { 4) What are the most Research } \\
\text { Approaches? }\end{array}$ & $\begin{array}{l}\text { Will help to Identify trends, limitation \& } \\
\text { opportunity of Research Approach. }\end{array}$ \\
\hline
\end{tabular}

\section{LITERATURE REVIEW}

Garvin describes quality from five different perspectives: transcendental view, user view, manufacturers view, product view and value based view. Quality must be monitored from the early phases such as analysis, design, implementation and maintenance phases. There are many models given. Some of the standard models are listed here:

McCall's et al model (1979) is one of the earliest model related to productivity gave emphasis on Triangle of Quality. McCall's quality model [60] addresses three perspectives: (i) Product operation (ii) Product revision (iii) Product transition. The model covers characteristics of quality which are efficiency, integrity, reliability, usability, accuracy, maintainability, testability, flexibility, interface, re-usability, transferability, interoperability. 
International Journal of Software Engineering \& Applications (IJSEA), Vol.2, No.4, October 2011

Boehm Quality Models $(1976,1978)$. This model attempts to qualitatively define the quality of software by a predefined set of attributes and metrics. He classified [54] General utility into As is utility, maintainability, portability which in turn were classified into characteristics like device independence, self-contentedness, Accuracy, Completeness, Integrity, Consistency, Device efficiency, Accessibility, communication, Self Descriptiveness, Structuredness, Conciseness, Legibility, Augment ability.

FURPS - The characteristics that are taken into consideration in FURPS model which are Functionality (include feature sets, capabilities and security), Usability (human factors, aesthetics, consistency in the user interface, online and context-sensitive help, wizards and agents, user documentation, and training materials), Reliability (frequency, severity of failure,

recoverability, predictability, accuracy, mean time between failure), Performance (speed, efficiency, availability, accuracy, throughput, response time, recovery time, and resource usage), Supportability (testability, extensibility, adaptability, maintainability, compatibility, configurability, serviceability, installability, Localizability)

Dromey's Quality Model [61] proposes a framework to evaluate requirement determination, design and implementation phases. The framework consists of three models, i.e. Requirement quality model, Design quality model and Implementation quality model. The high-level product properties for the implementation quality model include (i) Correctness measures (ii) Internal measures (iii) Contextual measures (iv) Descriptive measures. Dromey includes high level quality attributes: functionality, reliability, efficiency, usability, maintainability, portability, reusability and process maturity.

ISO 9000 - It provides guidelines for quality assurance. ISO 9001: 2000 [57] structured gives the requirement to develop a quality management system. The standard has eight clauses related to scope, references, terms \& definition, Requirement ( documents, quality manual, control of documents, control of records), management responsibility ( commitment, customer focus, quality policy, planning, management review, responsibility authority and communication), resource management, product realisation, measurement \& analysis \& improvement )

ISO 9126 [59] - ISO 9126 is an international standard for the evaluation of software. The standard is divided into four parts which addresses, the following subjects: quality model; external metrics; internal metrics; and quality in use metrics. The ISO 9126-1 software quality model identifies 6 main quality characteristics, namely: Functionality (Suitability, Accurateness. Interoperability, Compliance, Security), Reliability (Maturity, Fault tolerance, Recoverability, Understand ability), Usability (Learnability, Operability), Efficiency (Time behaviour, Resource behaviour, Analysability), Maintainability (Changeability, Stability, Testability, Adaptability) Portability (Installability, Conformance, Replaceability).

CMM [53] - It provides guidelines for conduction audits, testing activities and for process improvement. The approach classifies the maturity of an organisation into 5 levels. They are Initial (chaos), Repeatable (process management), defined (institutionalized), Managed (quantified), Optimizing (process improvement).

Georgiadou ( GEQUAMO) [55] - developed a customizable model which enables any stakeholder to construct their own model depending on their requirements. Georgiadou and Saika added two new characteristics extendibility and security.

\section{Process}

The main criteria for including journal, conference paper and other paper are the papers describing research on Software Quality and models. Papers were searched based on manual reading of titles and abstracts of all published paper in journals written in English. These journals were identified through reading reference lists of quality papers, searching on internet. In spite of many identified journals, it is possible that we have missed some of the journals, 
International Journal of Software Engineering \& Applications (IJSEA), Vol.2, No.4, October 2011

having papers on quality. Some of the papers were read number of times to categorize them. In total we have identified nearly 70 relevant paper found in different journals which are listed in the last.

Papers were identified and classified according to the property and categories listed in the Table 2. Classification aims at answering the Research Question listed in Table 1. It is a general purpose classification of Software Quality based on described criteria listed in Table 2. It is likely that some of the papers may have been incorrectly classified. This will be refined and improved in future by including maximum number of research papers.

The reason for analysing was that it gave a visual picture of software quality prediction research. It may also serve as a basis for deeper investigation of findings. We have included paper of scientifically high quality. Our research is specifically based on software quality models. It is quite possible that we have not included software industry experiences.

\section{RESULT}

\subsection{Which and how many journals include most paper on Software Quality?}

We found papers on software quality in many journals which are listed in the Appendix A. Most important journals which have listing of software quality papers are IEEE Transaction on Software Engineering, IEEE Transaction on Software, Software Quality Journals, and IEEE Handbook of Software Reliability Engineering.

Table 2. Summary for classification of Software Quality Model based on property

\begin{tabular}{|c|c|}
\hline Property & Category \\
\hline $\begin{array}{c}\text { Research } \\
\text { Topic }\end{array}$ & $\begin{array}{l}\text { Proposing a model (estimating quality, defects) i.e Probabilistic } \\
\text { model, Composite Model, Prediction of Quality (OOS), } \\
\text { Estimation of quality, Quality Classification, Composition and } \\
\text { Decomposition of Quality, Investigation, Forecasting \& } \\
\text { Monitoring of Quality, Improving, Evaluation, Assessment, } \\
\text { Optimizing, Quality Modelling, Novel Method, Empirical } \\
\text { Investigation, Filtering Quality attributes, Quality model based on } \\
\text { factors, Other Topics. }\end{array}$ \\
\hline $\begin{array}{l}\text { Approach / } \\
\text { Technique / } \\
\text { Algorithm / } \\
\text { Methodologies }\end{array}$ & $\begin{array}{l}\text { Regression Tree (Regression Technique), Poisson Regression } \\
\text { (PRM), Zero-inflated Poisson ( ZIP), Case Based Reasoning, } \\
\text { Analogy, Decision Tree, Data Sampling, Boosting, Simulation, } \\
\text { Neural network, Genetic Algorithm, Bayesian Network, Principal } \\
\text { Component Analysis, Adaptive Boosting, Data Mining } \\
\text { Techniques, Combination of Techniques, Statistical Method, } \\
\text { Fuzzy Logic, SLIM (Software Life cycle management Method), } \\
\text { Combination of estimates, Rule Based Induction (RI), Function } \\
\text { Points, Rules based, CART (Classification and Regression Tree } \\
\text { algorithm), Product based, Process based, Metrics Based, } \\
\text { Clustering, Classification Tree Disc Algorithm, Dependency } \\
\text { Graph and Analogy Based Reasoning, Rule Induction Models } \\
\text { And Others. }\end{array}$ \\
\hline
\end{tabular}


International Journal of Software Engineering \& Applications (IJSEA), Vol.2, No.4, October 2011

\begin{tabular}{|c|l|}
\hline $\begin{array}{c}\text { Research } \\
\text { Approach }\end{array}$ & $\begin{array}{l}\text { Theory, Survey, Experiment, Case Study, History based Own } \\
\text { experience, Real life evaluation, Review, Expert judgment. }\end{array}$ \\
\hline $\begin{array}{c}\text { Study } \\
\text { Context }\end{array}$ & Industrial software projects and others \\
\hline Data Sets & Data Set Applied \\
\hline
\end{tabular}

\subsection{Which is the most Investigated topic on Software Quality?}

Some topic has been identified by reading the abstract and reference list of paper which are listed in Table 2. Most investigated topic on software quality are like Proposing a Quality model based on Process [50], Product, Metrics[8], Defects[16]; Prediction or Estimation of quality; Proposing a Quality model for classification of modules [48]; Proposing a model for modelling Software Quality[22].

\subsection{What are the most Investigated methods or Techniques or Methodologies in Software Quality?}

The popularity of type of research was found to be highest during particular period of span. The diversity of new topic, technique are increasing with time i.e. Genetic Algorithm[47], [42], [14],[20], [18], Neural Network [29], Tree Decision [38] [45], Fuzzy logic[10], Classification and Regression Tree[52],[7] .There are also method and techniques used in prediction [28], [24], of software defects. We have included both conference paper and journal paper while listing methods, techniques etc. Recently used some of the methods and techniques are listed in Table 2.

\subsection{What are the Research Approaches applied?}

There are different approaches used by different researcher which are listed in Table 2. Some of the most often used research approaches are Case Study \& Experiment Designing

\section{CONCLUSION}

Researcher has predicted quality by proposing models using different approach, methodology, algorithm, techniques. They have evaluated model through case study, experiment, experts, opinions and survey. Data set is used in case of experiment designing. Based on 300 papers on software quality, we selected nearly seventy research papers related to software quality models and categorised them into eight research areas listed in Appendix B. All categories directly and indirectly speak of predicting quality using models, methods, technique, approaches. Therefore the area of search should be increased. The searching of paper manually is difficult. But searching it on internet becomes quite easy. Wide area of search and increase in number of research paper will increase the positively of result. 
International Journal of Software Engineering \& Applications (IJSEA), Vol.2, No.4, October 2011

\section{References}

[1] Parag C. Pendharkar, James A. Rodger, "A Probabilistic Model for Predicting Software Development Efforts", IEEE Transactions On Software Engineering, Vol. 31, No .7, July 2005.

[2] S. Balaswaminathan, "A Composite model used for Software Quality Assurance", www.stickyminds.com

[3] Ting-Peng Liang, James Jiang, Gary S. Klein, and Julie Yu-Chih Liu, "Software Quality as Influenced by Informational Diversity, Task Conflict, and Learning in Project Teams”, IEEE Transactions On Engineering Management, Vol. 57, No. 3, August 2010.

[4] Li Jin, Yin Guisheng, "Method of Constructing Model Transformation Rule Based on Reusable Pattern", International Conference on Computer Application and System Modelling (ICCASM 2010).

[5] Kehan Gao, Taghi M. khoshfgoftar, "An Empirical Investigation of Filter Attributes Selection Techniques for Software Quality Classification”, 2009, July 10-12, 2009.

[6] Reza Meimandi Parizi, Abdul Azim Abdul Ghani, "Towards Automated Monitoring and Forecasting of Probabilistic Quality Properties in Open Source Software (OSS): A Striking Hybrid Approach", 2010 Eighth ACIS International Conference on Software Engineering Research, Management and Applications.

[7] Taghi M. Khoshgoftaar, Edward B. Allen, Wendell D. Jones, John P. Hudepohi "Assessing Uncertain Prediction of Software Quality by Classification Tree Model".

[8] By Chuan Ho Loh, Sai Peck Lee, "Predicting the Quality of object oriented systems through a Quality Model based on Design Metrics and Data Mining Techniques”, 2009,

[9] Chris Seiffert, Taghi M. Khoshgoftarr, Jason Van Hulse, "Improving Software Quality Predictions With Data Sampling And Boosting", IEEE Transaction On System, Man And Cybernetics - Part A: System And Human. Vol 39 No.6, November 2009

[10] Jie Xu, Danny Ho and Luiz Fernando Capretz, "An Empirical Study on the Procedure to Derive Software Quality Estimation Models", International journal of computer science \& information Technology (IJCSIT) Vol.2, No.4, August 2010”.

[11] Reza Meimandi Parizi, Abdul Azim Abdul Ghani, Dept of Putra Malaysia, "Towards Automated Monitoring and Forecasting of Probabilities Quality Properties in Open source Software (OSS): A Striking Hybrid Approach”.

[12] Dennis J. Drown, Taghi M. Khoshgoftaar, Naeem Seiya, "Evolutionary Sampling And Software Quality Modeling Of High Assurance Systems”, IEEE Transaction On Systems, Man And Cybernetics, Systems And Humans, Vol 39, No-5, September 2009

[13] Peng Huang†, Jie Zhu, “A Multi-Instance Model for Software Quality in OO systems”, 2009 Fifth International Conference on Natural Computation.

[14] Yi Liu, Taghi Khoshgoftaar, Jenq-Foung Yao, "Building a Novel GP-Based Software Quality Classifier Using Multiple Validation Datasets”, 2007 IEEE.

[15] Wei Xiong1,, Xiao-Tun Wang1, Zhi-Xin Wu, "Study of a customer satisfaction-oriented model for outsourcing software quality management using Quality Function Deployment (QFD)", 2008 IEEE.

[16] A. Günes, Koru and Hongfang Liu, University of Maryland, Baltimore County,"Building Effective Defect - Prediction Models in Practice“, November / December, 2005 IEEE SOFTWARE.

[17] Taghi M Khoshgoftaar, Kehan Gao, “Count Models for Software quality”, IEEE Transaction on Reliability Vol. 56, No-2, June-2007.

[18] Taghi M. Khoshgoftaar, Member, IEEE, and Yi Liu, Member, IEEE, "A Multi-Objective Software Quality Classification Model Using Genetic Programming”, IEEE Transactions On Reliability, Vol. 56, No. 2, June 2007.

[19] Manish Agawal and Kaushal Charl, "Software Effort, Quality and Cycle Time: A study of CMM Level 5 Projects”, IEEE Transaction on Software Engineering, Vol No 33, No-3, March 2007.

[20] Taghi Khoshgoftaar, Jenq-Foung Yao, Yi Liu, "Building a Novel GP Based Software Quality Classifier Using Multiple Validation Datasets“, 2007 IEEE.

[21] Sahra Sedigh-Ali, Arif Ghafoor, "A Graph-Based Model for Component-Based Software Development", Proceedings of the 10th IEEE International Workshop on Object-Oriented RealTime Dependable Systems, 2005 IEEE 
International Journal of Software Engineering \& Applications (IJSEA), Vol.2, No.4, October 2011

[22] Taghi M. khoshgoftar, Erik Grleyn, Laurent Nguyen, Lofton Bulalrd, "Cost Sensitive Boosting Quality Modeling”, Proceedings of the 7th IEEE International Symposium on High Assurance Systems Engineering, 2002.

[23] Kenyer Domfnguez, Marai Perez, Anna C. Griman, Maryoly Ortega, Luis E. Mendoza, "Software Quality Model Based On Software Development Approaches"

[24] Lionel C. Briand, Member, Khaled El Emam, Bernd G. Freimut, Member, Oliver Laitenberger, "A Comprehensive Evaluation Of Capture-Recapture Models For Estimating Software Defect Content”, IEEE Transactions On Software Engineering, Vol. 26, No. 6, June 2000.

[25] Ming Huo, June Verner, Liming Zhu, Muhammad Ali Babar, "Software Quality and Agile Methods", Proceedings of the 28th Annual International Computer Software and Applications Conference (COMPSAC'04).

[26] Neelam Bawane, C.V.Srikrishna, "A Novel Method for Quantitative Assessment of Software Quality“, International Journal of Computer Science and Security.

[27] Victor R. Basili, Lionrl C. Briand, Walcello L.Melo “A Validation of Object-Oriented Design Metrices as Quality Indicators", IEEE Transactions on Software Engineering, Vol 22, No-10 October 1996.

[28] Norman E. Fenton, Member, IEEE Computer Society, And Martin Neil, Member, IEEE Computer Society, "A Critique Of Software Defect Prediction Models", IEEE Transactions On Software Engineering, Vol. 25, No. 5, September / October 1999.

[29] Taghi M. Khoshgoftaar, Edward B. Allen, Member, John P. Hudepohl, Stephen J. Aud "Application of Neural Networks to Software Quality Modelling of a Very Large Telecommunications System”, IEEE Transactions On Neural Networks, Vol. 8, No. 4, July 1997.

[30] Salah Bouktif, Bal'azs K'egl, Houari Sahraoui, "Combining Software Quality Predictive Models: An Evolutionary Approach “, Proceedings of the International Conference on Software Maintenance (ICSM.02). 2002 IEEE

[31] Yi Liu, Member, IEEE, Taghi M. Khoshgoftaar, Member, IEEE, and Naeem Seliya, Member, IEEE, "Evolutionary Optimization of Software Quality Modelling with Multiple Repositories", IEEE Transactions On Software Engineering.

[32] Wei Xiong, ZhiXin Wu1, "Research on the application of QFD (Quality Function Deployment) and konwlege management in the outsourcing software quality assurance”, 2009 International Conference on Computer Technology and Development.

[33] Fletcher J. Buckley, Senior Member, IEEE, AND Robert Poston, Senior Member, IEEE, "Software Quality Assurance”, IEEE Transactions On Software Engineering, Vol. Se-10, No. 1, January 1984.

[34] Per Runeson and Peter Isacsson, "Software Quality Assurance - Concepts and Misconceptions", 1998 IEEE.

[35] Michel Defamie, Patrick Jacobs, Jacques Thollembeck, "Software Reliability: Assumption, Realities and Data".

[36] Nicolas Bettenburg and Ahmed E. Hassan, "Studying the Impact of Social Structures on Software Quality”, 18th IEEE International Conference on `Program Comprehension.

[37] Katsuyuki Yasuda Shigeru Yamada, "The Concept and Practice of Software Quality Assurance in Japan in the Global Era, ", Proceedings of 'the 7th IEEE International Symposium on High Assurance Systems Engineering (HASE’02), 2002 IEEE.

[38] Taghi M. Khoshgoftaar, Naeem Saliya, "Tree based software quality models for fault Prediction “, Proceedings of the Eighth IEEE `Symposium on Software Metrics (Metrics.02), 2002.

[39] Beatriz Marín, Giovanni Giachetti, Oscar Pastor, Tanja E. J. Vos, “A Tool for Automatic Defect Detection in Models used in Model-Driven Engineering ", Seventh International Conference on the Quality of Information and Communications Technology.

[40] Yas. A. Alsultanny, Ahmed M. Wohaishi, "Requirements of Software Quality Assurance Model”, 2009 Second International Conference on Environmental and Computer. Science.

[41] Omar Alshathry, Helge Janicke, Hussein Zedan, Abdullah AlHussein, "Quantitative Quality Assurance Approach”, 2009 International Conference on New Trends in Information and Service Science.

[42] Yi Liu, Taghi M. Khoshgoftaar, "Reducing Overfitting in Genetic Programming Models For Software Quality Classification", 2004, Proceedings of the Eighth IEEE International Symposium on High Assurance Systems Engineering (HASE’04).

[43] Alessandro Bianchi, Danilo Caivano, Giuseppe Visaggio, "Quality Models Reuse: 
International Journal of Software Engineering \& Applications (IJSEA), Vol.2, No.4, October 2011

Experimentation on Field”, 2002 IEEE Proceedings of the 26th Annual International Computer Software and Applications Conference (COMPSAC'02).

[44] Stefan Wagner, Klaus Lochmann, Sebastian Winter, Andreas Goeb, Michael Klaes, “Quality Models in Practice: A Preliminary Analysis”, Third International Symposium on Empirical Software Engineering and Measurement.

[45] Taghi M. Khoshgoftaar, Edward B. Allen, "Improving Tree-Based Models of Software Quality with Principal Components Analysis”, 2000 IEEE.

[46] Erricsion Nicolas Tesla R \& D Centre "How to improve software development process using Mathematical models for quality prediction and elements of Six Sigma Methodology"

[47] Taghi M. Khoshgoftaar, Yi Liu “Genetic Programming Model for Software Quality Classification”, Proceedings of the 6th IEEE International Symposium on High Assurance Systems Engineering.

[48] Taghi M. Khoshgoftaar, Yi Liu, Naeem Saliya, "Genetic Programming based Decision Tree For Software Quality Classification”, 2003 IEEE...

[49] Hiranmay Ghosh,” A Comparison of ISO 9000 and SEI/CMM for Software Engineering Organizations".

[50] Taghi M. Khoshgoftaar, Edward B. Allen, Robert Halstead, Gary P. Trio, "Process Measures for Predicting Software Quality”, Predicting Software Quality”,1997 IEEE.

[51] Kazuhira Okumoto,"A Statistical Method for Software Quality Control”, IEEE Transactions On Software Engineering, Vol., No.12, December 1985.

[52] Taghi M. Khoshgoftaar, Wendell D. Jones, John P. Hudepohl, Nortel, "Using Classification Trees for Software Quality Models: Lessons Learned “.

[53] Software Engineering Institute, "The Capability Maturity Model: Guidelines for Improving the Software Process “, MA: Addision - Wesley, 1994.

[54] B.W. Bohem et al. J. R. Brown, H. Kaspar, M. Lipow, G. McLeod, and M. Merritt, "Characteristics of Software Quality", North Holland, (1978)

[55] E. Georgiadou "Software Process and Product Improvement: A historical Perspective", International Journal of Cybernetics, Volume1, No1, pp. 172 - 197, Jan 2003

[56] ISO 9000: 2005 Quality management systems Fundamentals and vocabulary, 2005.

[57] ISO 9001: 2000 Quality management systems Requirements, 2001.

[58] ISO 9004: 2000 Quality management systems Guidelines for performance improvement, 2000.

[59] ISO / IEC, IS 9126-1, "Software Engineering - Product Quality - Part 1: Quality Model", Geneva Switzerland: International Organization for Standization, 2001.

[60] J. A McCall, P. K, Richards and G. F. Wallers, "Factors in software quality ", Griffiths Air Force Base, N. Y: Rome Air Development Center Air Force Systems Command, 1977.

[61] R.G. Dromey, "Software product quality: Theory, model and practices. Software quality Institute”, Griffith University, Brisbane, Technical Report, 1999.

[62] Yiannis Kanellopoulos, Panos Antonellis, Dimitris Antoniou, ChristosMakris, Evangelos Theodoridis, Christos Tjortjis, and Nikos Tsirakis, " Code Quality Evaluation Methodology using the ISO/IEC 9126 Standard", International Journal of Software Engineering \& Applications (IJSEA), Vol.1, No.3, July 2010. 
International Journal of Software Engineering \& Applications (IJSEA), Vol.2, No.4, October 2011

\section{Appendix: A: List of Journal Name}

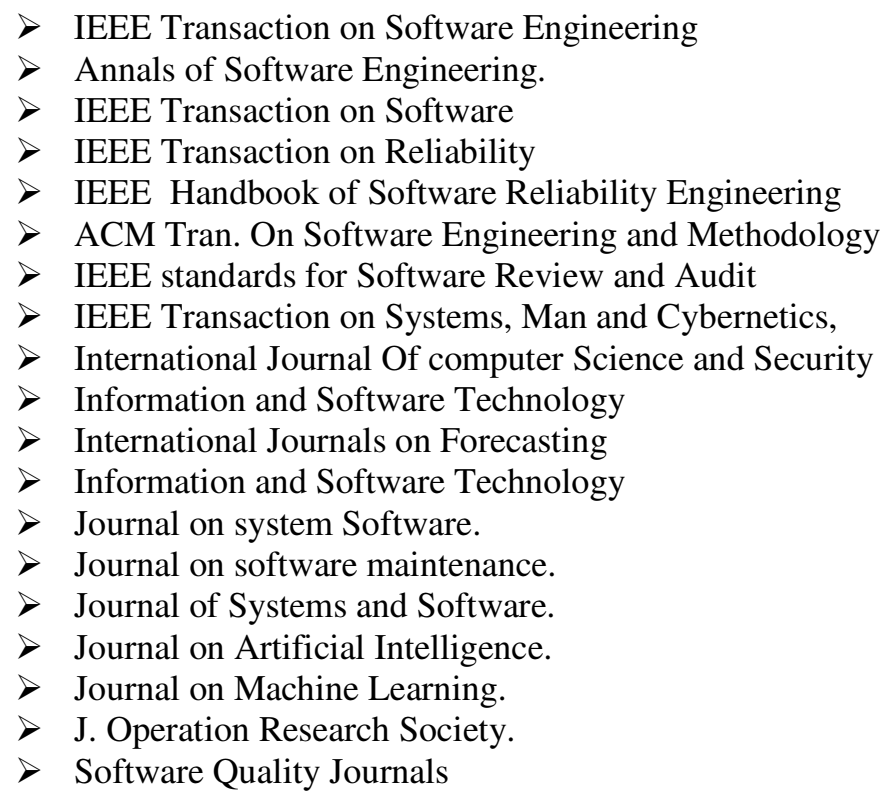

\section{Appendix B: Classification Aspects}

\section{Research Topic}

$>$ Proposing a model (Probabilistic model, Composite Model, Novel Method) based on Process, Product, and Metrics.

Proposing a Software Quality model based on Defects

$>$ Prediction / Estimation/ Investigation / Evaluation / Optimizing/ Assessment of Quality model

$>$ Proposing a model for Quality Classification

$>$ Proposing a model for Predicting software defect

$>$ Proposing a model for Modelling software quality

$>$ Composition and Decomposition of Quality, Filtering Quality attributes.

\section{Estimation Approach}

$>$ Tree Decision

$>$ Genetic Algorithm

$>$ Neural Network

$>$ Fuzzy logic

$>$ Classification and Regression Tree

$>$ Sampling \& Boosting [9]

$>$ Metrics, Process \& Product Based [41], [23], [2] 
International Journal of Software Engineering \& Applications (IJSEA), Vol.2, No.4, October 2011

\section{Research Approach.}

$>$ Case Study

$>$ Experiment Designing

\section{Study Context}

$>$ Data Sets

\section{Authors}

Ashwin Tomar is currently working as an Assistant Professor and is with Siddhant Institute of Computer Application under University of Pune. His research interests include Software Engineering, Software Testing, Quality Engineering, Reuse, and Database Management. He is also member of various committees.

Dr. Vilas M. Thakare is Professor and Head in Computer Science, Faculty of Engineering \& Technology, and is with Post Graduate Department of Computer Science, Sant Gadge Baba Amravati University, and Amravati. Maharashtra, India. His research interests include Computer Architectures, AI, Robotics, and Software Engineering. He has published more than 40 papers in these areas and guided more than 300 projects. He is associated with various universities i.e. Dr. B.A.M.U ( Aurangabad), S.R.T.M.U

Nanded), Indira Sangit Kala University (MP), Bilaspur University (Guru Ghasidas), RD University ( Jabalpur), DAVV (Indore), (RTMNU) Nagpur University, YCMOU. Dr. Vilas M. Thakare is a Member of the IEEE Institute of Engineers, ISTE, and CSI. He has

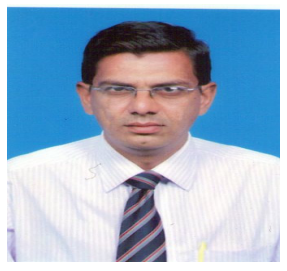
served on as Chairman and Member of various committees like Academic Council, Faculty of Engineering \& Science, BOS (Comp. Science), IT Committee, Networking Committee, NAAC, BUTR, ASU, DRC, RRC, SEC, CAS, NSD, AICTE (WR). He has served on technical program committees of various conferences, symposia, and workshops. 